University of Nebraska - Lincoln

DigitalCommons@University of Nebraska - Lincoln

Faculty Publications from the Department of Electrical \& Computer Engineering, Department Electrical and Computer Engineering

$2-2011$

\title{
Constant Power Control of DFIG Wind Turbines With Supercapacitor Energy Storage
}

\author{
Liyan Qu \\ University of Nebraska-Lincoln, lqu2@unl.edu \\ Wei Qiao \\ University of Nebraska-Lincoln, wqiao@engr.unl.edu
}

Follow this and additional works at: https://digitalcommons.unl.edu/electricalengineeringfacpub

Part of the Electrical and Computer Engineering Commons

Qu, Liyan and Qiao, Wei, "Constant Power Control of DFIG Wind Turbines With Supercapacitor Energy Storage" (2011). Faculty Publications from the Department of Electrical and Computer Engineering. 189. https://digitalcommons.unl.edu/electricalengineeringfacpub/189

This Article is brought to you for free and open access by the Electrical \& Computer Engineering, Department of at DigitalCommons@University of Nebraska - Lincoln. It has been accepted for inclusion in Faculty Publications from the Department of Electrical and Computer Engineering by an authorized administrator of DigitalCommons@University of Nebraska - Lincoln. 


\title{
Constant Power Control of DFIG Wind Turbines With Supercapacitor Energy Storage
}

\author{
Liyan Qu, Member, IEEE, and Wei Qiao, Member, IEEE
}

\begin{abstract}
With the increasing penetration of wind power into electric power grids, energy storage devices will be required to dynamically match the intermittency of wind energy. This paper proposes a novel two-layer constant power control scheme for a wind farm equipped with doubly fed induction generator (DFIG) wind turbines. Each DFIG wind turbine is equipped with a supercapacitor energy storage system (ESS) and is controlled by the low-layer wind turbine generator (WTG) controllers and coordinated by a high-layer wind farm supervisory controller (WFSC). The WFSC generates the active power references for the low-layer WTG controllers according to the active power demand from or generation commitment to the grid operator; the low-layer WTG controllers then regulate each DFIG wind turbine to generate the desired amount of active power, where the deviations between the available wind energy input and desired active power output are compensated by the ESS. Simulation studies are carried out in PSCAD/EMTDC on a wind farm equipped with 15 DFIG wind turbines to verify the effectiveness of the proposed control scheme.
\end{abstract}

Index Terms-Constant power control (CPC), doubly fed induction generator (DFIG), energy storage, supervisory controller, wind turbine.

\section{INTRODUCTION}

W IND TURBINE generators (WTGs) are usually controlled to generate maximum electrical power from wind under normal wind conditions. However, because of the variations of the wind speed, the generated electrical power of a WTG is usually fluctuated. Currently, wind energy only provides about $1 \%-2 \%$ of the U.S.'s electricity supply. At such a penetration level, it is not necessary to require WTGs to participate in automatic generation control, unit commitment, or frequency regulation.

However, it is reasonable to expect that wind power will be capable of becoming a major contributor to the nation's and world's electricity supply over the next three decades. For instance, the European Wind Energy Association has set a target to satisfy more than $22 \%$ of European electricity demand

Manuscript received December 11, 2009; revised April 16, 2010; accepted May 31, 2010. Date of publication November 9, 2010; date of current version January 19, 2011. Paper 2009-IACC-474.R1, presented at the 2009 Industry Applications Society Annual Meeting, Houston, TX, October 4-8, and approved for publication in the IEEE TRANSACTIONS ON INDUSTRY APPLICATIONS by the Industrial Automation and Control Committee of the IEEE Industry Applications Society. This work was supported by the U.S. National Science Foundation under Grant ECCS-0901218 and CAREER Award ECCS-0954938.

The authors are with the Department of Electrical Engineering, University of Nebraska-Lincoln, Lincoln, NE 68588-0511 USA (e-mail: liyanqu @ieee.org; wqiao@engr.unl.edu).

Color versions of one or more of the figures in this paper are available online at http://ieeexplore.ieee.org.

Digital Object Identifier 10.1109/TIA.2010.2090932 with wind power by 2030 [1]. In the U.S., according to a report [2] by the Department of Energy, it is feasible to supply $20 \%$ of the nation's electricity from wind by 2030 . At such high levels of penetration, it will become necessary to require WTGs to supply a desired amount of active power to participate in automatic generation control or frequency regulation of the grid [3]. However, the intermittency of wind resources can cause high rates of change (ramps) in power generation [4], which is a critical issue for balancing power systems. Moreover, to optimize the economic performance of power systems with high penetrations of wind power, it would be desired to require WTGs to participate in unit commitment, economic dispatch, or electricity market operation [5]. In practice, short-term wind power prediction [6] is carried out to help WTGs provide these functions. However, even using the state-of-the-art methods, prediction errors are present [5]. Under these conditions, the replacement power is supported by reserves, which, however, can be more expensive than base electricity prices [7].

To enable WTGs to effectively participate in frequency and active power regulation, unit commitment, economic dispatch, and electricity market operation, energy storage devices will be required to dynamically match the intermittency of wind energy. In [8], the authors investigated and compared different feasible electric energy storage technologies for intermittent renewable energy generation, such as wind power. Currently, pumped water and compressed air are the most commonly used energy storage technologies for power grids due to their low capital costs [9]. However, these two technologies are heavily dependent on geographical location with relatively low round-trip efficiency. Compared with their peers, batteries and supercapacitors are more efficient, have a quicker response to demand variations, and are easy to develop and ubiquitously deployable. Compared to batteries, supercapacitors have a higher power density, higher round-trip efficiency, longer cycle life, and lower capital cost per cycle [10]. Therefore, supercapacitors are a good candidate for short-term (i.e., seconds to minutes) energy storage that enables WTGs to provide the function of frequency regulation and effectively participate in unit commitment and electricity market operation. The use of supercapacitors [10] or batteries [11]-[13] as energy storage devices for WTGs has been studied by some researchers. However, these studies only focused on control and operation of individual WTGs and did not investigate the issues of WTGs to participate in grid regulation.

This paper proposes a novel two-layer constant power control (CPC) scheme for a wind farm equipped with doubly fed induction generator (DFIG) wind turbines [14], where each WTG is equipped with a supercapacitor energy storage system 


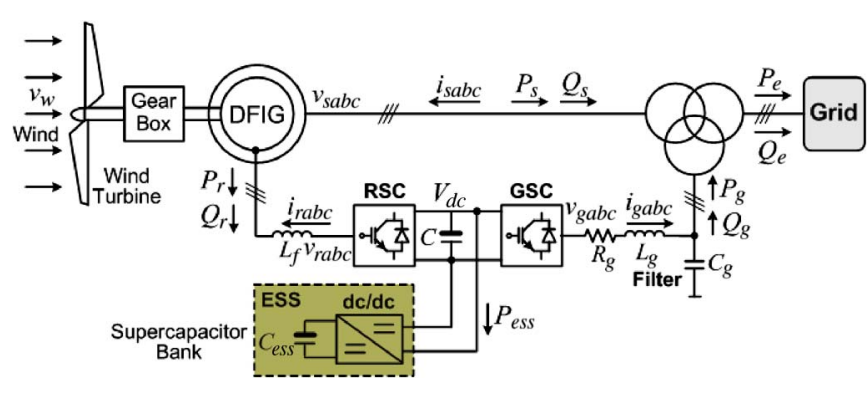

Fig. 1. Configuration of a DFIG wind turbine equipped with a supercapacitor ESS connected to a power grid.

(ESS). The CPC consists of a high-layer wind farm supervisory controller (WFSC) and low-layer WTG controllers. The highlayer WFSC generates the active power references for the lowlayer WTG controllers of each DFIG wind turbine according to the active power demand from the grid operator. The low-layer WTG controllers then regulate each DFIG wind turbine to generate the desired amount of active power, where the deviations between the available wind energy input and desired active power output are compensated by the ESS. Simulation studies are carried out in PSCAD/EMTDC for a wind farm equipped with 15 DFIG wind turbines to verify the effectiveness of the proposed control scheme.

\section{DFIG Wind Turbine With Energy Storage}

Fig. 1 shows the basic configuration of a DFIG wind turbine equipped with a supercapacitor-based ESS. The low-speed wind turbine drives a high-speed DFIG through a gearbox. The DFIG is a wound-rotor induction machine. It is connected to the power grid at both stator and rotor terminals. The stator is directly connected to the grid, while the rotor is fed through a variable-frequency converter, which consists of a rotor-side converter (RSC) and a grid-side converter (GSC) connected back to back through a dc link and usually has a rating of a fraction $(25 \%-30 \%)$ of the DFIG nominal power. As a consequence, the WTG can operate with the rotational speed in a range of $\pm 25 \%-30 \%$ around the synchronous speed, and its active and reactive powers can be controlled independently.

In this paper, an ESS consisting of a supercapacitor bank and a two-quadrant dc/dc converter is connected to the dc link of the DFIG converters. The ESS serves as either a source or a sink of active power and therefore contributes to control the generated active power of the WTG. The value of the capacitance of the supercapacitor bank can be determined by

$$
C_{\mathrm{ess}}=\frac{2 P_{n} T}{V_{\mathrm{SC}}^{2}}
$$

where $C_{\text {ess }}$ is in farads, $P_{n}$ is the rated power of the DFIG in watts, $V_{\mathrm{SC}}$ is the rated voltage of the supercapacitor bank in volts, and $T$ is the desired time period in seconds that the ESS can supply/store energy at the rated power $\left(P_{n}\right)$ of the DFIG.

The use of an ESS in each WTG rather than a large single central ESS for the entire wind farm is based on two reasons. First, this arrangement has a high reliability because the failure of a single ESS unit does not affect the ESS units in other WTGs. Second, the use of an ESS in each WTG can reinforce

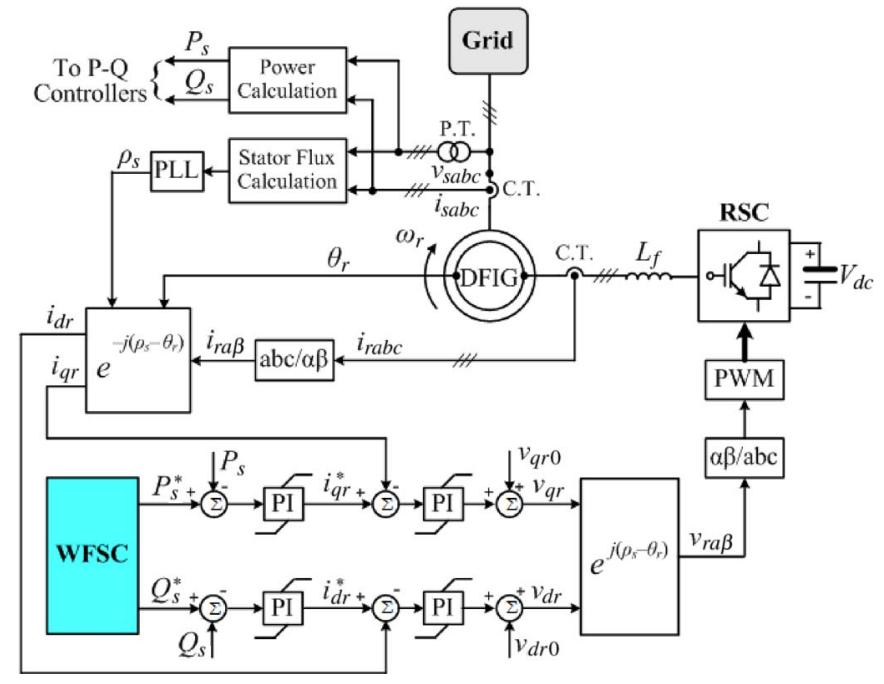

Fig. 2. Overall vector control scheme of the RSC.

the dc bus of the DFIG converters during transients, thereby enhancing the low-voltage ride through capability of the WTG [10].

\section{Control of Individual DFIG Wind Turbine}

The control system of each individual DFIG wind turbine generally consists of two parts: 1) the electrical control of the DFIG and 2) the mechanical control of the wind turbine blade pitch angle [14], [15] and yaw system. Control of the DFIG is achieved by controlling the RSC, the GSC, and the ESS (see Fig. 1). The control objective of the RSC is to regulate the stator-side active power $P_{s}$ and reactive power $Q_{s}$ independently. The control objective of the GSC is to maintain the dc-link voltage $V_{\mathrm{dc}}$ constant and to regulate the reactive power $Q_{g}$ that the GSC exchanges with the grid. The control objective of the ESS is to regulate the active power $P_{g}$ that the GSC exchanges with the grid. In this paper, the mechanical control of the wind turbine blade pitch angle is similar to that in [15].

\section{A. Control of the RSC}

Fig. 2 shows the overall vector control scheme of the RSC, in which the independent control of the stator active power $P_{s}$ and reactive power $Q_{s}$ is achieved by means of rotor current regulation in a stator-flux-oriented synchronously rotating reference frame [16]. Therefore, the overall RSC control scheme consists of two cascaded control loops. The outer control loop regulates the stator active and reactive powers independently, which generates the reference signals $i_{d r}^{*}$ and $i_{q r}^{*}$ of the $d$ - and $q$-axis current components, respectively, for the inner-loop current regulation. The outputs of the two current controllers are compensated by the corresponding cross-coupling terms $v_{d r 0}$ and $v_{q r 0}$ [14], respectively, to form the total voltage signals $v_{d r}$ and $v_{q r}$. They are then used by the pulsewidth modulation (PWM) module to generate the gate control signals to drive the RSC. The reference signals of the outer-loop power controllers are generated by the high-layer WFSC. 


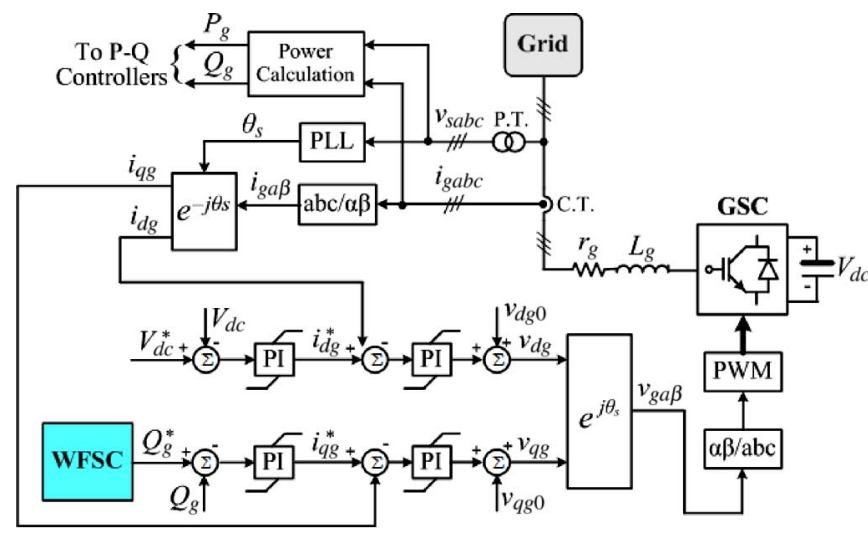

Fig. 3. Overall vector control scheme of the GSC.

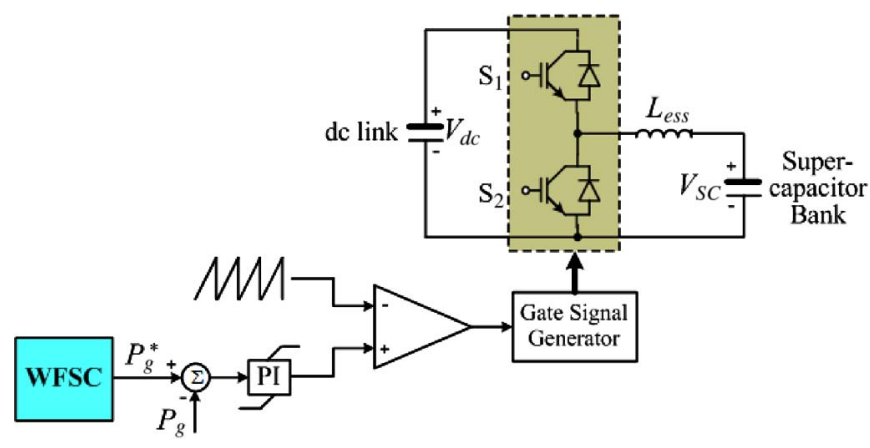

Fig. 4. Configuration and control of the ESS.

\section{B. Control of the GSC}

Fig. 3 shows the overall vector control scheme of the GSC, in which the control of the dc-link voltage $V_{\mathrm{dc}}$ and the reactive power $Q_{g}$ exchanged between the GSC and the grid is achieved by means of current regulation in a synchronously rotating reference frame [16]. Again, the overall GSC control scheme consists of two cascaded control loops. The outer control loop regulates the dc-link voltage $V_{\mathrm{dc}}$ and the reactive power $Q_{g}$, respectively, which generates the reference signals $i_{d g}^{*}$ and $i_{q g}^{*}$ of the $d$ - and $q$-axis current components, respectively, for the inner-loop current regulation. The outputs of the two current controllers are compensated by the corresponding crosscoupling terms $v_{d g 0}$ and $v_{q g 0}$ [14], respectively, to form the total voltage signals $v_{d g}$ and $v_{q g}$. They are then used by the PWM module to generate the gate control signals to drive the GSC. The reference signal of the outer-loop reactive power controller is generated by the high-layer WFSC.

\section{Configuration and Control of the ESS}

Fig. 4 shows the configuration and control of the ESS. The ESS consists of a supercapacitor bank and a two-quadrant $\mathrm{dc} / \mathrm{dc}$ converter connected to the dc link of the DFIG. The $\mathrm{dc} / \mathrm{dc}$ converter contains two insulated-gate bipolar transistor (IGBT) switches $\mathrm{S}_{1}$ and $\mathrm{S}_{2}$. Their duty ratios are controlled to regulate the active power $P_{g}$ that the GSC exchanges with the grid. In this configuration, the $\mathrm{dc} / \mathrm{dc}$ converter can operate in two different modes, i.e., buck or boost mode, depending on the status of the two IGBT switches. If $\mathrm{S}_{1}$ is open, the $\mathrm{dc} / \mathrm{dc}$

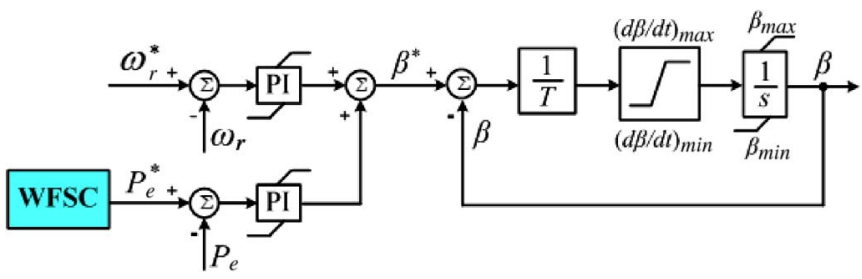

Fig. 5. Blade pitch control for the wind turbine.

converter operates in the boost mode; if $\mathrm{S}_{2}$ is open, the $\mathrm{dc} / \mathrm{dc}$ converter operates in the buck mode. The duty ratio $D_{1}$ of $\mathrm{S}_{1}$ in the buck mode can be approximately expressed as

$$
D_{1}=\frac{V_{\mathrm{SC}}}{V_{\mathrm{dc}}}
$$

and the duty ratio $D_{2}$ of $\mathrm{S}_{2}$ in the boost mode is $D_{2}=1-D_{1}$. In this paper, the nominal dc voltage ratio $V_{\mathrm{SC}, n} / V_{\mathrm{dc}, n}$ is 0.5 , where $V_{\mathrm{SC}, n}$ and $V_{\mathrm{dc}, n}$ are the nominal voltages of the supercapacitor bank and the DFIG dc link, respectively. Therefore, the nominal duty ratio $D_{1, n}$ of $\mathrm{S}_{1}$ is 0.5 .

The operating modes and duty ratios $D_{1}$ and $D_{2}$ of the dc/dc converter are controlled depending on the relationship between the active powers $P_{r}$ of the RSC and $P_{g}$ of the GSC. If $P_{r}$ is greater than $P_{g}$, the converter is in buck mode and $D_{1}$ is controlled, such that the supercapacitor bank serves as a sink to absorb active power, which results in the increase of its voltage $V_{\mathrm{SC}}$. On the contrary, if $P_{g}$ is greater than $P_{r}$, the converter is in boost mode and $D_{2}$ is controlled, such that the supercapacitor bank serves as a source to supply active power, which results in the decrease of its voltage $V_{\mathrm{SC}}$. Therefore, by controlling the operating modes and duty ratios of the dc/dc converter, the ESS serves as either a source or a sink of active power to control the generated active power of the WTG. In Fig. 4, the reference signal $P_{g}^{*}$ is generated by the high-layer WFSC.

\section{Wind Turbine Blade Pitch Control}

Fig. 5 shows the blade pitch control for the wind turbine, where $\omega_{r}$ and $P_{e}\left(=P_{s}+P_{g}\right)$ are the rotating speed and output active power of the DFIG, respectively. When the wind speed is below the rated value and the WTG is required to generate the maximum power, $\omega_{r}$ and $P_{e}$ are set at their reference values, and the blade pitch control is deactivated. When the wind speed is below the rated value, but the WTG is required to generate a constant power less than the maximum power, the active power controller may be activated, where the reference signal $P_{e}^{*}$ is generated by the high-layer WFSC and $P_{e}$ takes the actual measured value. The active power controller adjusts the blade pitch angle to reduce the mechanical power that the turbine extracts from wind. This reduces the imbalance between the turbine mechanical power and the DFIG output active power, thereby reducing the mechanical stress in the WTG and stabilizing the WTG system. Finally, when the wind speed increases above the rated value, both $\omega_{r}$ and $P_{e}$ take the actual measured values, and both the speed and active power controllers are activated to adjust the blade pitch angle. 


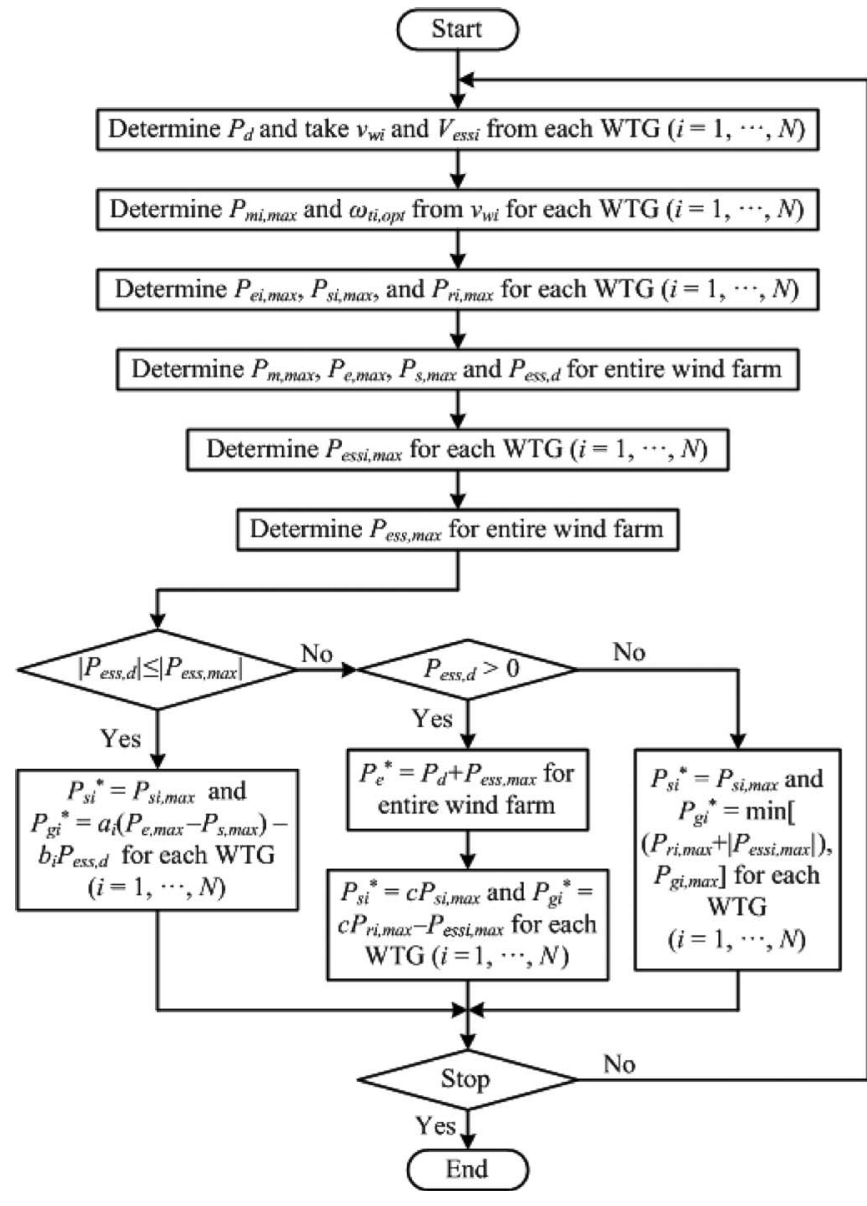

Fig. 6. Flowchart of implementation of the WFSC.

\section{WIND FARM SUPERVISORY CONTROL}

The objective of the WFSC is to generate the reference signals for the outer-loop power controllers of the RSC and GSC, the controller of the dc/dc converter, and the blade pitch controller of each WTG, according to the power demand from or the generation commitment to the grid operator. The implementation of the WFSC is described by the flowchart in Fig. 6, where $P_{d}$ is the active power demand from or the generation commitment to the grid operator; $v_{w i}$ and $V_{\text {ess } i}$ are the wind speed in meters per second and the voltage of the supercapacitor bank measured from WTG $i(i=1, \ldots, N)$, respectively; and $N$ is the number of WTGs in the wind farm. Based on $v_{w i}$, the optimal rotational speed $\omega_{t i \text {,opt }}$ in radians per second of the wind turbine can be determined, which is proportional to the wind speed $v_{w i}$ at a certain pitch angle $\beta_{i}$

$$
\omega_{t i, \mathrm{opt}}=k\left(\beta_{i}\right) v_{w i}
$$

where $k$ is a constant at a certain value of $\beta_{i}$. Then, the maximum mechanical power $P_{m i \text {,max }}$ that the wind turbine extracts from the wind can be calculated by the well-known wind turbine aerodynamic characteristics

$$
P_{m i, \max }=\frac{1}{2} \rho_{i} A_{r} v_{w i}^{3} C_{P i}\left(\lambda_{i, \mathrm{opt}}, \beta_{i}\right)
$$

where $\rho_{i}$ is the air density in kilograms per cubic meter; $A_{r}=$ $\pi R^{2}$ is the area in square meters swept by the rotor blades, with $R$ being the blade length in meters; and $C_{P i}$ is the power coefficient, which is a function of both tip-speed ratio $\lambda_{i}$ and the blade pitch angle $\beta_{i}$, where $\lambda_{i}$ is defined by

$$
\lambda_{i}=\frac{\omega_{t i} R}{v_{w i}} .
$$

In (4), $\lambda_{i, \text { opt }}$ is the optimal tip-speed ratio when the wind turbine rotates with the optimal speed $\omega_{t i, \mathrm{opt}}$ at the wind speed $v_{w i}$.

Given $P_{m i, \max }$, the maximum active power $P_{e i, \max }$ generated by the WTG can be estimated by taking into account the power losses of the WTG [14]

$$
P_{e i, \max }=P_{m i, \max }-P_{L i}=P_{s i, \max }+P_{r i, \max }
$$

where $P_{L i}$ is the total power losses of WTG $i$, which can be estimated by the method in [14]; $P_{s i, \max }$ and $P_{r i, \max }$ are the maximum DFIG stator and rotor active powers of WTG $i$, respectively. In terms of the instantaneous variables in Fig. 1, the stator active power $P_{s}$ can be written in a synchronously rotating $d q$ reference frame [16] as follows:

$$
\begin{aligned}
P_{s} & =\frac{3}{2}\left(v_{d s} i_{d s}+v_{q s} i_{q s}\right) \\
& \approx \frac{3}{2}\left[\omega_{s} L_{m}\left(i_{q s} i_{d r}-i_{d s} i_{q r}\right)+r_{s}\left(i_{d s}^{2}+i_{q s}^{2}\right)\right]
\end{aligned}
$$

where $v_{d s}$ and $v_{q s}$ are the $d$ - and $q$-axis voltage components of the stator windings, respectively; $i_{d s}$ and $i_{q s}$ are the stator $d$ - and $q$-axis current components, respectively; $i_{d r}$ and $i_{q r}$ are the rotor $d$ - and $q$-axis current components, respectively; $\omega_{s}$ is the rotational speed of the synchronous reference frame; and $r_{s}$ and $L_{m}$ are the stator resistance and mutual inductance, respectively. Similarly, the rotor active power is calculated by

$$
\begin{aligned}
P_{r} & =\frac{3}{2}\left(v_{d r} i_{d r}+v_{q r} i_{q r}\right) \\
& \approx \frac{3}{2}\left[-s \omega_{s} L_{m}\left(i_{q s} i_{d r}-i_{d s} i_{q r}\right)+r_{r}\left(i_{d r}^{2}+i_{q r}^{2}\right)\right]
\end{aligned}
$$

where $v_{d r}$ and $v_{q r}$ are the $d$ - and $q$-axis voltage components of the rotor windings, respectively; $s$ is the slip of the DFIG defined by

$$
s=\left(\omega_{s}-\omega_{r}\right) / \omega_{s}
$$

where $\omega_{r}$ is the DFIG rotor speed. (7) and (8) yield

$$
s=-\frac{P_{r}-3 i_{r}^{2} r_{r}}{P_{s}-3 i_{s}^{2} r_{s}}
$$

where $i_{s}=\sqrt{i_{d s}^{2}+i_{q s}^{2}} / 2$ and $i_{r}=\sqrt{i_{d r}^{2}+i_{q r}^{2}} / 2$. If neglecting the stator copper loss $3 i_{s}^{2} r_{s}$ and rotor copper loss $3 i_{r}^{2} r_{r}$ of the DFIG, the relationship between the stator and rotor active powers can be approximated by

$$
P_{r}=-s P_{s}
$$

According to (6) and (10) [or (11)], $P_{s i, \max }$ and $P_{r i, \max }$ of each WTG can be determined. Then, the total maximum mechanical power $P_{m, \max }$, DFIG output active power $P_{e, \max }$, and stator 


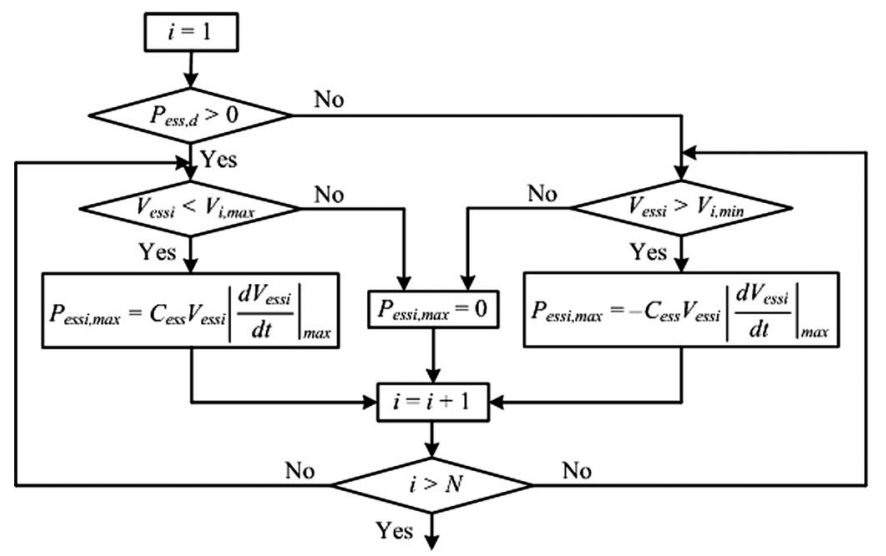

Fig. 7. Flowchart of determination of $P_{\mathrm{ess} i, \max }$ for each WTG.

active power $P_{s, \max }$ of all WTGs in the wind farm can be calculated as

$$
\begin{aligned}
P_{m, \max } & =\sum_{i=1}^{N} P_{m i, \max } \\
P_{e, \max } & =\sum_{i=1}^{N} P_{e i, \max } \\
P_{s, \max } & =\sum_{i=1}^{N} P_{s i, \max } .
\end{aligned}
$$

In order to supply constant power $P_{d}$ to the grid, the deviation $P_{\text {ess }, d}$ between the demand/commitment $P_{d}$ and the maximum generation $P_{e, \max }$ is the power that should be stored in or supplied from the ESSs of the WTGs

$$
P_{\mathrm{ess}, d}=P_{e, \max }-P_{d}
$$

On the other hand, the capability of each ESS to store or supply power depends on the capacitance $C_{\text {ess }}$ and the voltage $V_{\text {ess } i}$ of the supercapacitor bank. During normal operation, $V_{\mathrm{ess} i}$ must be maintained within the following range:

$$
V_{i, \min }<V_{\mathrm{ess} i}<V_{i, \max }
$$

where $V_{i, \max }$ and $V_{i, \min }$ are the maximum and minimum operating voltages of the supercapacitor bank, respectively. The maximum power $P_{\text {essi, max }}$ that can be exchanged between the supercapacitor bank and the DFIG dc link of WTG $i$ can be determined by

$$
P_{\mathrm{ess} i, \max }= \pm C_{\mathrm{ess}} V_{\mathrm{ess} i}\left|\frac{d V_{\mathrm{ess} i}}{d t}\right|_{\max }
$$

where $\left|d V_{\mathrm{ess} i} / d t\right|_{\max }$ is the maximum rate of voltage variations of the supercapacitor bank, which is related to the current limits of the supercapacitor bank. In (17), the positive sign indicates storing energy, while the negative sign indicates supplying energy by the ESS. The calculation of $P_{\text {ess } i \text {, max }}$ for each WTG is subjected to (16). Fig. 7 shows how to determine $P_{\text {ess } i \text {, max }}$ for each WTG. If $P_{\text {ess, } d}>0$, extra power needs to be stored in the ESSs. In this case, if $V_{\mathrm{ess} i}<V_{i, \max }, P_{\mathrm{ess} i, \max }$ is calculated by (17) and takes the positive sign; otherwise, the ESS cannot store any power and $P_{\text {essi,max }}=0$. On the contrary, if $P_{\mathrm{ess}, d}<0$, active power needs to be supplied from the ESSs. In this case,

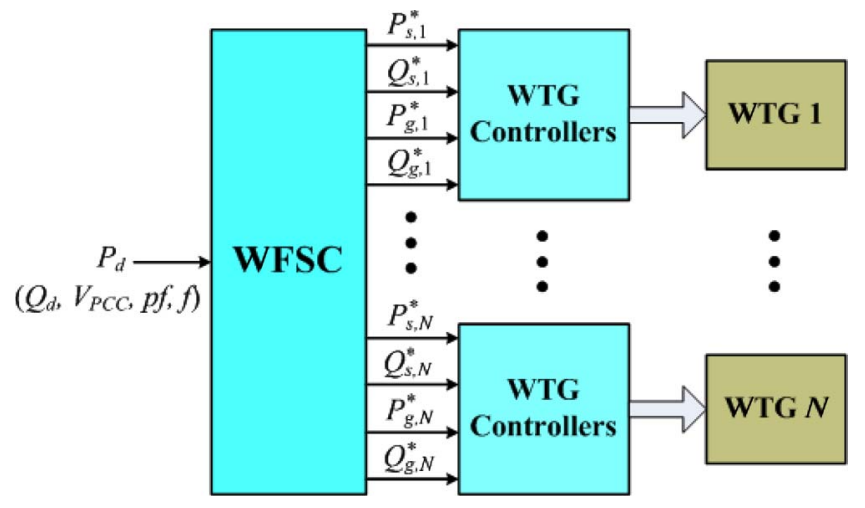

Fig. 8. Proposed two-layer CPC scheme for the wind farm.

if $V_{\text {ess } i}>V_{i, \min }, P_{\text {essi,max }}$ is calculated by (17) and takes the negative sign; otherwise, the ESS cannot supply any power and $P_{\text {ess } i, \max }=0$.

As shown in Fig. 6, once $P_{\text {essi, max }}$ of each WTG is determined, the total maximum power $P_{\text {ess, max }}$ that can be exchanged between the supercapacitor bank and the DFIG dc link of all WTGs can be determined by

$$
P_{\text {ess }, \max }=\sum_{i=1}^{N} P_{\text {ess } i, \max } .
$$

Finally, depending on the relationship of $P_{\mathrm{ess}, d}$ and $P_{\mathrm{ess}, \max }$, the reference signals $P_{s i}^{*}$ (see Fig. 2) and $P_{g i}^{*}$ (see Fig. 4) of each WTG can be determined. Specifically, if $\left|P_{\mathrm{ess}, d}\right| \leq\left|P_{\mathrm{ess}, \max }\right|$, $P_{s i}^{*}$ and $P_{g i}^{*}$ can be determined directly, as shown in Fig. 6, where the partition coefficients $a_{i}$ 's are calculated by

$$
a_{i}=\frac{P_{r i, \max }}{P_{e, \max }-P_{s, \max }}
$$

and the partition coefficients $b_{i}$ 's are calculated by

$$
b_{i}=\frac{P_{\mathrm{ess} i, \max }}{P_{\mathrm{ess}, \max }} .
$$

The coefficients $a_{i}$ and $b_{i}$ have the following feature:

$$
\sum_{i=1}^{N} a_{i}=1 \quad \sum_{i=1}^{N} b_{i}=1 .
$$

If $\left|P_{\text {ess }, d}\right|>\left|P_{\text {ess,max }}\right|$, depending on the sign of $P_{\mathrm{ess}, d}, P_{s i}^{*}$ and $P_{g i}^{*}$ can be determined, as shown in Fig. 6. If $P_{\mathrm{ess}, d}$ is positive, the ESSs of the WTGs store active power, and the total active power generated by all DFIGs is $P_{e}^{*}$, which is less than $P_{e, \max }$. Therefore, a scaling factor $c$ is defined as follows:

$$
c=\frac{P_{e}^{*}}{P_{e, \max }}
$$

and $P_{s i}^{*}$ and $P_{g i}^{*}$ can be determined by using the scaling factor. If $P_{\mathrm{ess}, d}$ is negative, the ESSs of the WTGs supply active power, the RSC of each WTG is controlled to generate the maximum stator active power $P_{s i \text { max }}$, and the ESS of each WTG is controlled to generate active power of $P_{g i}^{*}$, where $P_{g i \text {, max }}$ is the maximum value of $P_{g i}$ depending on the maximum power capacity of the GSC.

Fig. 8 shows the block diagram of the proposed two-layer CPC scheme for the wind farm, where $P_{d}$ is the active power 


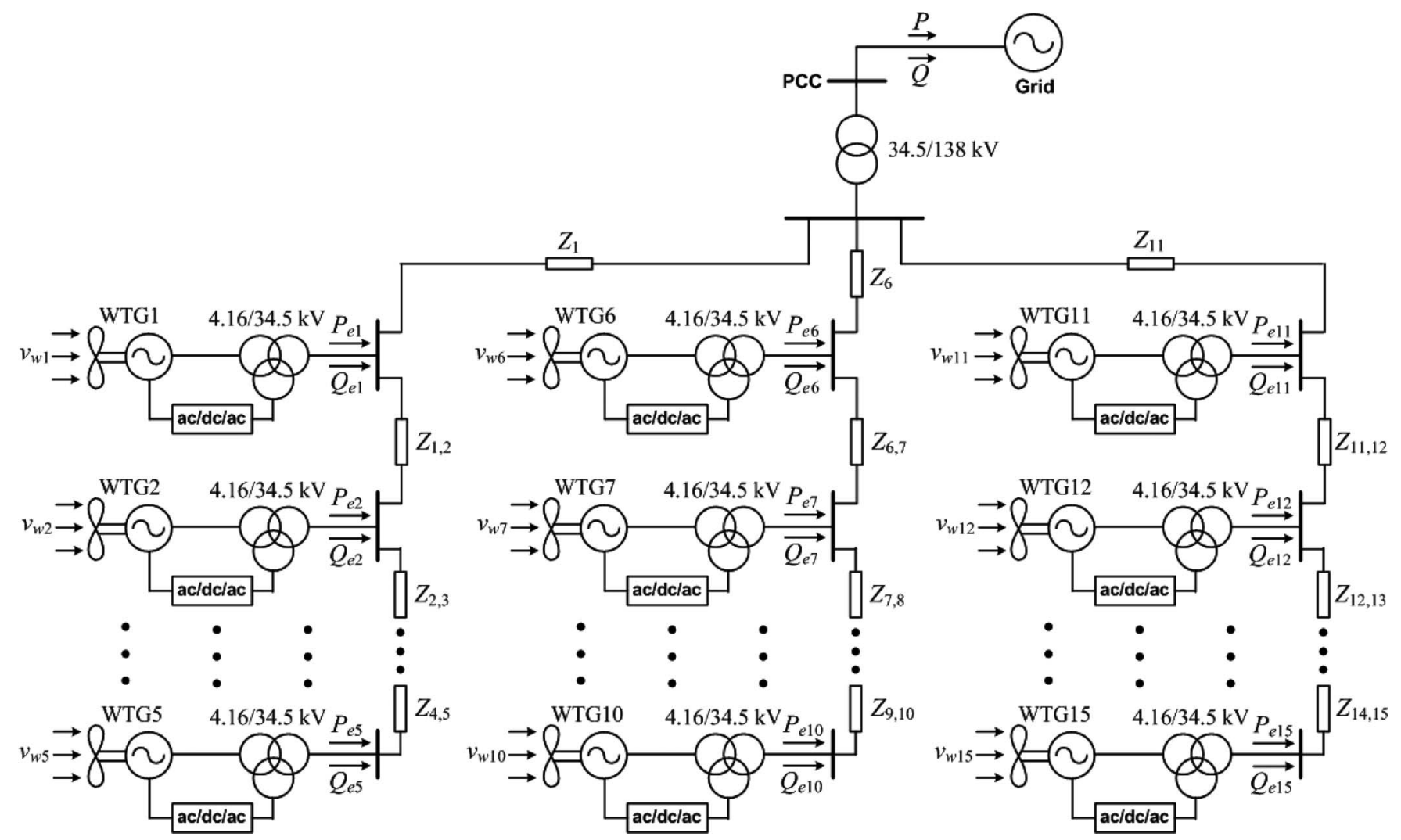

Fig. 9. Configuration of a wind farm equipped with 15 DFIG wind turbines connected to a power grid.

demand from or commitment to the grid operator. In practice, the value of $P_{d}$ should take into account the generation capability of the wind farm and should be subjected to the following limit:

$$
P_{d} \leq \bar{P}_{e, \max }
$$

where $\bar{P}_{e, \max }$ is the average value of $P_{e, \max }$ over the period that $P_{d}$ will be constant and the value of $P_{e, \max }$ during the period can be obtained from short-term wind power prediction [6]. This function allows the wind farm to be able to actively participate in automatic generation control, unit commitment, or frequency regulation of the grid, where the deviations between the available wind energy input and desired active power output are compensated by the ESSs. Under the condition of (23) and the ESS of a WTG has been fully filled up, then the power reference of the blade pitch controller in Fig. 5 is set at $P_{d}$ by the WFSC to adjust the pitch angle to reduce the WTG output active power to $P_{d}$. Moreover, the implementation of the WFSC (Fig. 6) subject to (23) ensures that the use of the ESS does not need to increase the rating of the RSC or the GSC.

The reactive power references of the RSC (Fig. 2) and GSC (Fig. 3) controllers can be determined by controlling the power factor $(p f)$ or the voltage $\left(V_{\mathrm{PCC}}\right)$ at the point of common coupling (PCC) of the wind farm at the desired value or to supply a desired amount of reactive power as required by the grid operator. However, these issues are not in the scope of this paper. In this paper, the reactive power references of all RSC and GSC controllers are simply set as zero.

\section{Simulation Results}

Simulation studies are carried out for a wind farm with 15 DFIG wind turbines (see Fig. 9) to verify the effectiveness of the proposed control scheme under various operating conditions. Each DFIG wind turbine (see Fig. 1) has a 3.6-MW power capacity [14], [15]. The total power capacity of the wind farm is $54 \mathrm{MW}$. Each DFIG wind turbine is connected to the internal network of the wind farm through a 4.16/34.5-kV voltage step-up transformer. The high-voltage terminals of all transformers in the wind farm are connected by $34.5-\mathrm{kV}$ power cables to form the internal network of the wind farm. The entire wind farm is connected to the utility power grid through a $34.5 / 138-\mathrm{kV}$ voltage step-up transformer at PCC to supply active and reactive powers of $P$ and $Q$, respectively. In this paper, the power grid is represented by an infinite source. The ESS of each WTG is designed to continuously supply/store $20 \%$ of the DFIG rated power for approximately $60 \mathrm{~s}$. Then, the total capacitance of the supercapacitor bank can be obtained from (1). The parameters of the WTG, the ESS, and the power network are listed in the Appendix. Some typical results are shown and discussed in this section.

\section{A. CPC During Variable Wind Speed Conditions}

Fig. 10 shows the wind speed profiles of WTG1 $\left(v_{w 1}\right)$, WTG6 $\left(v_{w 6}\right)$, and WTG11 $\left(v_{w 11}\right)$. The wind speeds across the three WTGs vary in a range of $\pm 3 \mathrm{~m} / \mathrm{s}$ around their mean value of $12 \mathrm{~m} / \mathrm{s}$. The variations of wind speed cause fluctuations of the electrical quantities of the WTGs. As shown in Fig. 11, if the wind farm is not equipped with any energy storage devices 

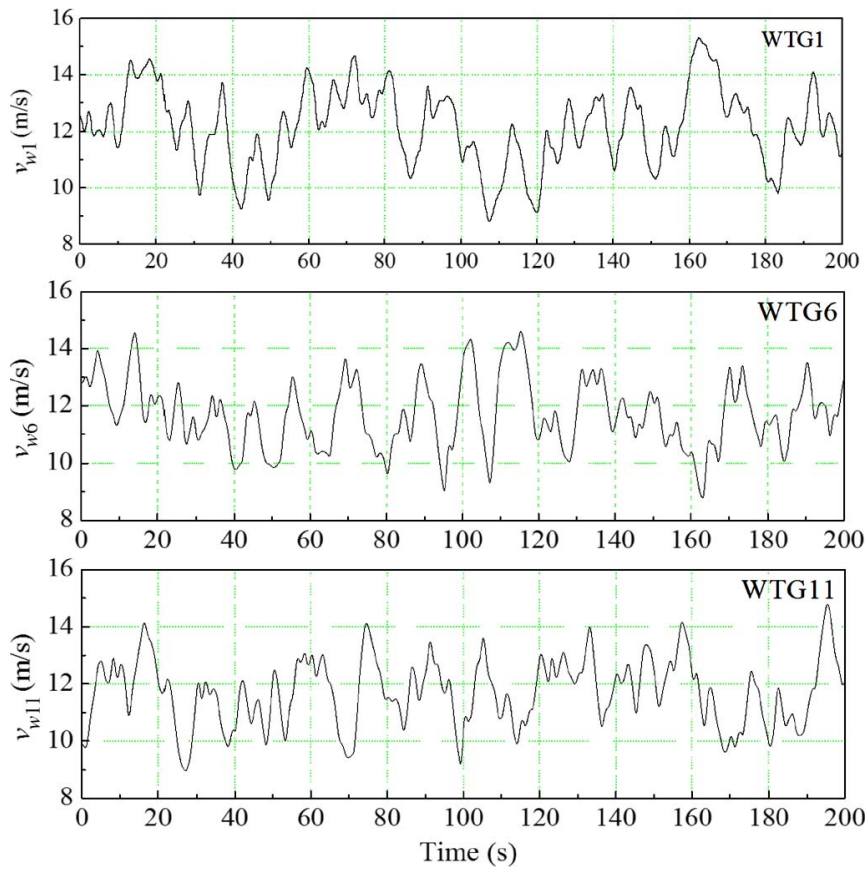

Fig. 10. Wind speed profiles of WTG1, WTG6, and WTG11.

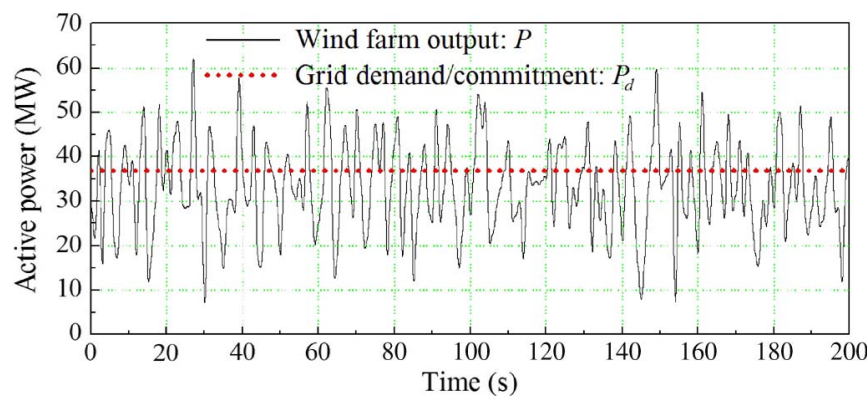

Fig. 11. Comparison of the wind farm power output (measured at PCC) and the constant power demand from or commitment to the grid operator: Without ESSs and the proposed CPC scheme.

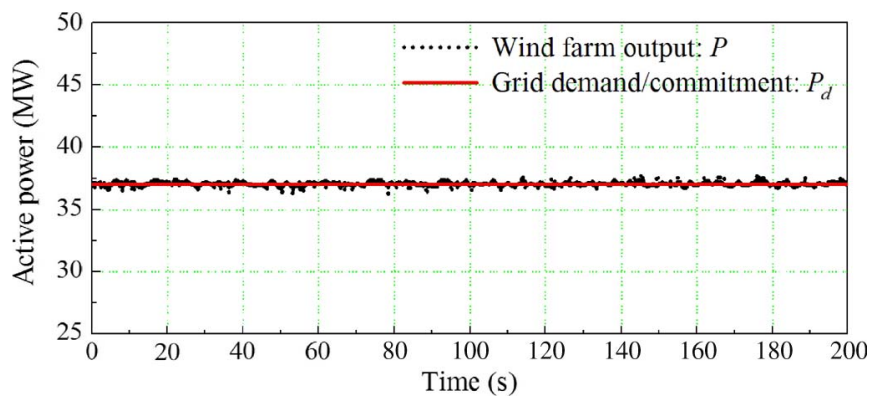

Fig. 12. Comparison of the wind farm power output (measured at PCC) and the constant power demand from or commitment to the grid operator: With ESSs and the proposed CPC scheme.

or the proposed CPC scheme, the wind speed variations in the wind farm result in significant fluctuations of the total output active power at the PCC. The wind farm power output deviates significantly from the active power demand or commitment. In future electric power grids where the penetration of wind power is high (e.g., 20\%), such active power fluctuations can bring severe problems to grid operation.

Fig. 12 compares the total output active power of the wind farm with the power demand from or commitment to the grid

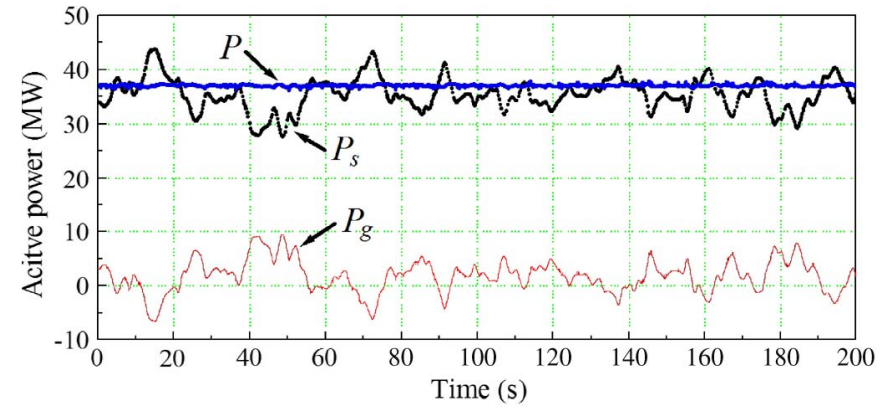

Fig. 13. Active powers of all WTGs and the wind farm.

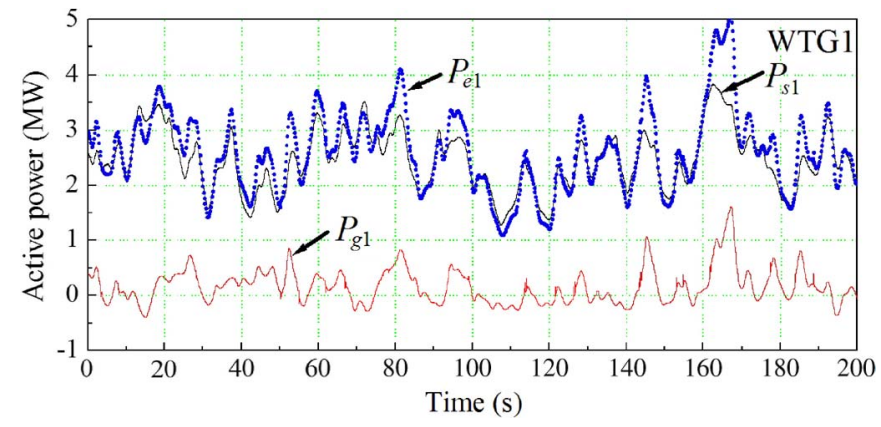

Fig. 14. Stator active power $\left(P_{s 1}\right)$, GSC active power $\left(P_{g 1}\right)$, and total active power output $\left(P_{e 1}\right)$ of WTG1.

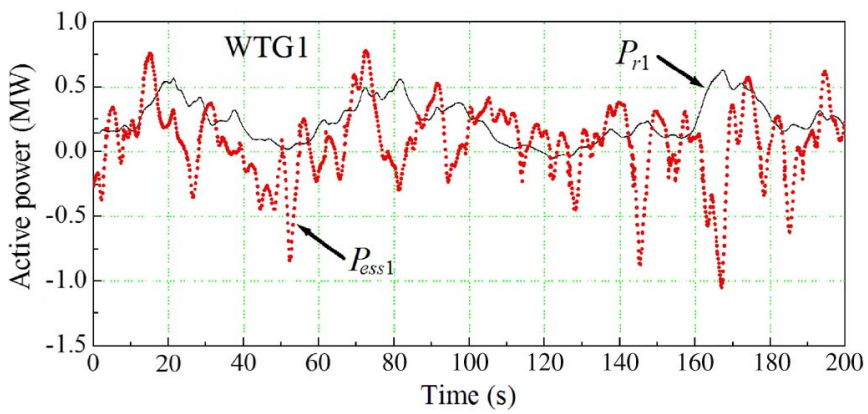

Fig. 15. Rotor active power $\left(P_{r 1}\right)$ and active power stored in or supplied by the ESS $\left(P_{\text {ess } 1}\right)$ of WTG1.

operator, where each WTG is equipped with an ESS as shown in Fig. 1. The ESS stores energy when the WTG generates more active power than the demand/commitment and supplies energy when the WTG generates less active power than the demand/commitment. The resulting output power of the wind farm is therefore controlled at a constant value as required by the grid operator.

Fig. 13 shows the total stator active power $P_{s}$ and the total GSC active power $P_{g}$ of all WTGs, as well as the total output active power $P$ (measured at PCC) of the wind farm. Through the control of the proposed CPC scheme, the variations of the stator active power are exactly compensated by the variations of the GSC active power. Consequently, the total output active power of the wind farm is constant. However, the total output active power $P_{e i}$ of each individual WTG, which is the sum of the stator active power $P_{s i}$ and the GSC active power $P_{g i}$, is usually not constant, as shown in Fig. 14 for WTG 1. The deviations between the RSC active power $\left(P_{r i}\right)$ and the GSC active power $\left(P_{g i}\right)$ of each WTG are stored in or supplied by the ESS $\left(P_{\text {essi }}\right)$, as shown in Fig. 15 for WTG 1. 

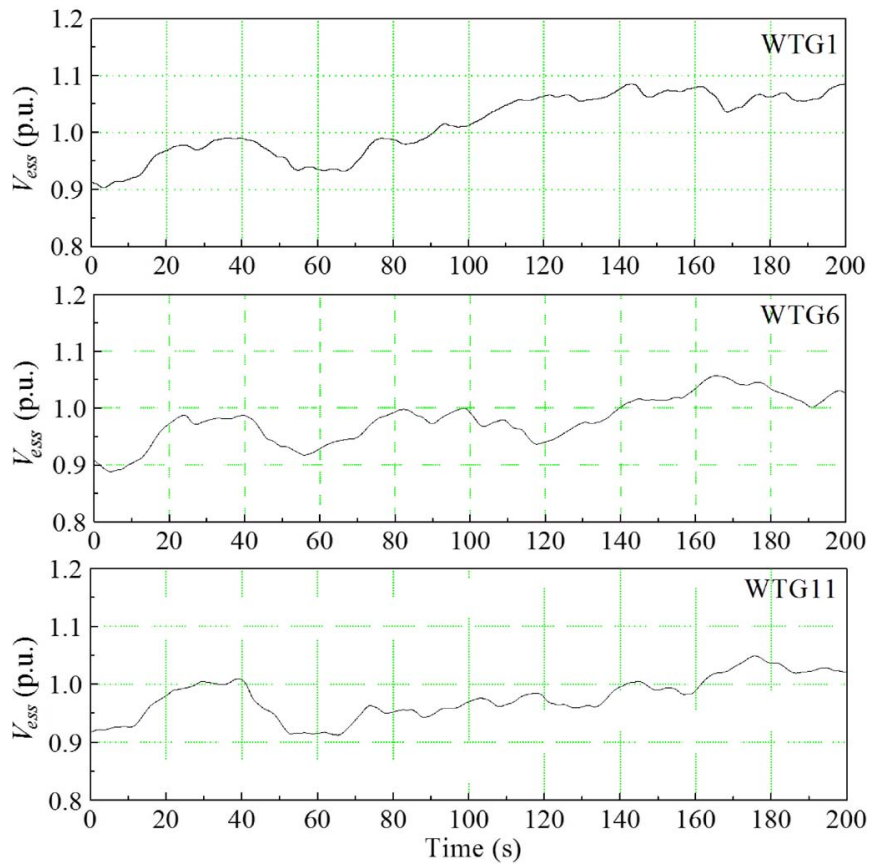

Fig. 16. Voltages of the supercapacitor banks of WTG1, WTG6, and WTG11.

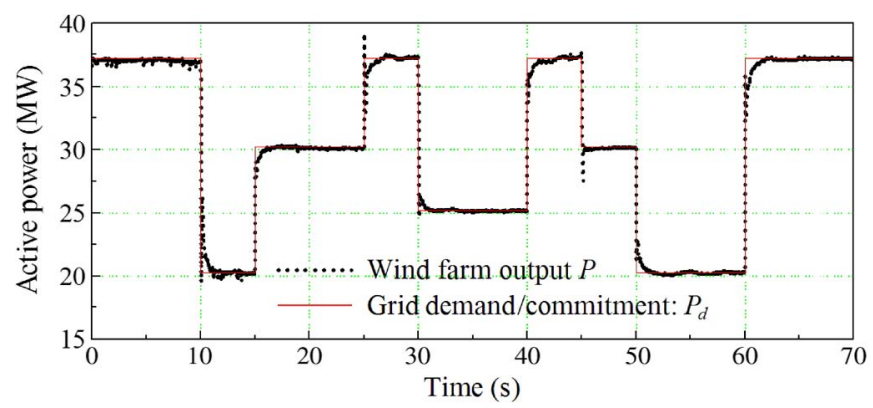

Fig. 17. Power tracking performance of the wind farm during step changes in demand from or commitment to the grid operator.

Fig. 16 shows the voltages of the supercapacitor banks of WTG1, WTG6, and WTG11. These voltages are always maintained within the operating limits of $[0.5,1.1]$ p.u.

\section{B. Power Tracking During Step Changes in Demand/Commitment}

Under the same wind conditions as in the previous tests, the power demand from or commitment to the grid operator is now step changed from time to time. The wind farm is controlled by the proposed CPC scheme to track the variations of the power demand. Fig. 17 shows the power tracking performance of the wind farm. The generated active power by the wind farm dynamically tracks the power demand/commitment with good precision. This power tracking capability cannot be achieved without using the ESSs or the proposed control scheme.

Fig. 18 shows the total active power outputs of WTG1 and WTG5. Although the total output power of the wind farm is controlled to be constant during each time interval, as shown in Fig. 17, the total active power output of each individual WTG is not constant. Under the regulation of the proposed CPC scheme, including the blade pitch control, the output power of each WTG is always kept within its limits of 3.6 MW.

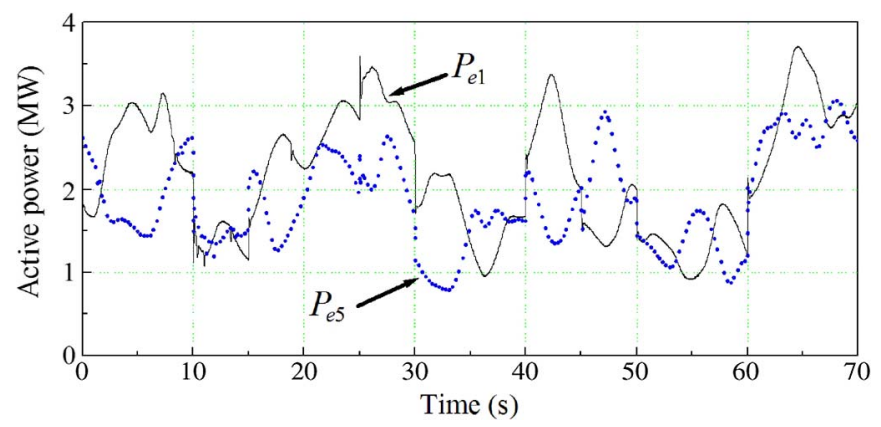

Fig. 18. Total active power outputs of WTG1 $\left(P_{e 1}\right)$ and WTG5 $\left(P_{e 5}\right)$ during step changes in demand from or commitment to the grid operator.

\section{Conclusion}

This paper has proposed a novel two-layer CPC scheme for a wind farm equipped with DFIG wind turbines. Each wind turbine is equipped with a supercapacitor-based ESS, which is connected to the dc link of the DFIG through a two-quadrant dc/dc converter. The ESS serves as either a source or a sink of active power to control the generated active power of the DFIG wind turbine. Each individual DFIG wind turbine and its ESS are controlled by low-layer WTG controllers, which are coordinated by a high-layer WFSC to generate constant active power as required by or committed to the grid operator.

Simulation studies have been carried out for a wind farm equipped with 15 DFIG wind turbines to verify the effectiveness of the proposed CPC scheme. Results have shown that the proposed CPC scheme enabled the wind farm to effectively participate in unit commitment and active power and frequency regulations of the grid. The proposed system and control scheme provides a solution to help achieve high levels of penetration of wind power into electric power grids.

\section{APPENDIX}

Wind turbine (Fig. 1): Rated capacity $=3.6 \mathrm{MW}$, number of blades $=3$, rotor diameter $=104 \mathrm{~m}$, swept area $=8495 \mathrm{~m}^{2}$, rotor speed $($ variable $)=8.5-15.3 \mathrm{r} / \mathrm{min}$, and inertia constant $=4.29 \mathrm{~s}$.

Wound-rotor induction generator (Fig. 1): Nominal power $=$ $3.6 \mathrm{MW}$, nominal stator voltage $=4.16 \mathrm{kV}$, power factor $p f=-0.9 \sim+0.9, r_{s}=0.0079$ p.u., $r_{r}=0.025$ p.u., $r_{m}=$ 66.57 p.u., $L_{l s}=0.07937$ p.u., $L_{l r}=0.40$ p.u., $L_{m}=4.4$ p.u., inertia constant $=0.9 \mathrm{~s}$, and base frequency $f=60 \mathrm{~Hz}$.

ESS (Figs. 1 and 4): $C=20 \mathrm{mF}, C_{\text {ess }}=20 \mathrm{~F}, L_{\mathrm{ess}}=$ $50 \mathrm{mH}$, nominal dc-link voltage $=4 \mathrm{kV}$, and nominal voltage of the supercapacitor bank $=2 \mathrm{kV}$. The supercapacitor bank consists of 3700 2.7-V 3000-F cells.

Power network (Fig. 9): Each power cable is represented by a $\Pi$ equivalent circuit where $Z_{1}=Z_{6}=Z_{11}=0.0738+$ $j 0.1050 \Omega$ and the shunt admittance is $-j B_{1} / 2=-j 2.6901 \times$ $10^{-5} \mathrm{~S} ; Z_{1,2}=Z_{6,7}=Z_{11,12}=0.0771+j 0.1148 \Omega$ and the shunt admittance is $-j B_{2} / 2=-j 2.2263 \times 10^{-5} \mathrm{~S} ; Z_{2,3}=$ $Z_{7,8}=Z_{12,13}=0.1870+j 0.1444 \Omega$ and the shunt admittance is $-j B_{3} / 2=-j 1.6388 \times 10^{-5} \mathrm{~s} ; Z_{3,4}=Z_{8,9}=Z_{13,14}=$ $0.2756+j 0.1558 \Omega$ and the shunt admittance is $-j B_{4} / 2=$ $-j 1.4842 \times 10^{-5} \mathrm{~S}$; and $Z_{4,5}=Z_{9,10}=Z_{14,15}=0.3658+$ $j 0.1591 \Omega$ and the shunt admittance is $-j B_{4} / 2=-j 1.3296 \times$ $10^{-5} \mathrm{~S}$. The shunt admittances are not shown in Fig. 9. 


\section{REFERENCES}

[1] "Focus on 2030: EWEA aims for 22\% of Europe's electricity by 2030," Wind Directions, pp. 25-34, Nov./Dec. 2006.

[2] 20\% Wind Energy By 2030: Increasing Wind Energy's Contribution to U.S. Electricity Supply, U.S. Department of Energy, Jul. 2008.

[3] W. Qiao and R. G. Harley, "Grid connection requirements and solutions for DFIG wind turbines," in Proc. IEEE Energy Conf., Atlanta, GA, Nov. 17-18, 2008, pp. 1-8.

[4] Wind Generation \& Total Load in the BPA Balancing Authority: DOE Bonneville Power Administration, U.S. Department of Energy. [Online]. Available: http://www.transmission.bpa.gov/business/operations/Wind/ default.aspx

[5] R. Piwko, D. Osborn, R. Gramlich, G. Jordan, D. Hawkins, and K. Porter, "Wind energy delivery issues: Transmission planning and competitive electricity market operation," IEEE Power Energy Mag., vol. 3, no. 6, pp. 47-56, Nov./Dec. 2005.

[6] L. Landberg, G. Giebel, H. A. Nielsen, T. Nielsen, and H. Madsen, "Shortterm prediction-An overview," Wind Energy, vol. 6, no. 3, pp. 273-280, Jul./Sep. 2003.

[7] M. Milligan, B. Kirby, R. Gramlich, and M. Goggin, Impact of Electric Industry Structure on High Wind Peneration Potential, Nat. Renewable Energy Lab., Golden, CO, Tech. Rep. NREL/TP-550-46273. [Online]. Available: http://www.nrel.gov/docs/fy09osti/46273.pdf

[8] J. P. Barton and D. G. Infield, "Energy storage and its use with intermittent renewable energy," IEEE Trans. Energy Convers., vol. 19, no. 2, pp. 441448, Jun. 2004

[9] D. Rastler, "Electric energy storage, an essential asset to the electric enterprise: Barriers and RD\&D needs," California Energy Commission Staff Workshop Energy Storage Technol., Policies Needed Support California's RPS Goals 2020, Sacramento, CA, Apr. 2, 2009.

[10] C. Abbey and G. Joos, "Supercapacitor energy storage for wind energy applications," IEEE Trans. Ind. Appl., vol. 43, no. 3, pp. 769-776, May/Jun. 2007.

[11] B. S. Borowy and Z. M. Salameh, "Dynamic response of a stand-alone wind energy conversion system with battery energy storage to wind gust," IEEE Trans. Energy Convers., vol. 12, no. 1, pp. 73-78, Mar. 1997.

[12] M.-S. Lu, C.-L. Chang, W.-J. Lee, and L. Wang, "Combining the wind power generation system with energy storage equipments," IEEE Trans. Ind. Appl., vol. 45, no. 6, pp. 2109-2115, Nov./Dec. 2009.

[13] A. Yazdani, "Islanded operation of a doubly-fed induction generator (DFIG) wind-power system with integrated energy storage," in Proc. IEEE Canada Elect. Power Conf., Montreal, QC, Canada, Oct. 25-26, 2007, pp. 153-159.

[14] W. Qiao, W. Zhou, J. M. Aller, and R. G. Harley, "Wind speed estimation based sensorless output maximization control for a wind turbine driving a DFIG," IEEE Trans. Power Electron., vol. 23, no. 3, pp. 1156-1169, May 2008.

[15] W. Qiao, G. K. Venayagamoorthy, and R. G. Harley, "Real-time implementation of a STATCOM on a wind farm equipped with doubly fed induction generators," IEEE Trans. Ind. Appl., vol. 45, no. 1, pp. 98-107, Jan./Feb. 2009.

[16] D. W. Novotny and T. A. Lipo, Vector Control and Dynamics of AC Drives. Oxford, U.K.: Oxford Univ. Press, 2000.

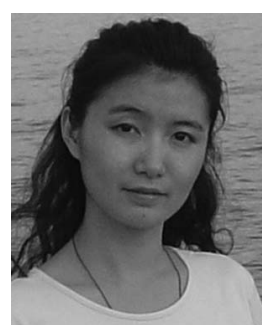

Liyan Qu (S'05-M'08) received the B.Eng. (with honors) and M.Eng. degrees in electrical engineering from Zhejiang University, Hangzhou, China, in 1999 and 2002, respectively, and the Ph.D. degree in electrical engineering from the University of Illinois at Urbana-Champaign, in 2007.

From 2007 to 2009, she was an Application Engineer with Ansoft Corporation. Currently, she is a Senior Lecturer of electrical engineering at the University of Nebraska-Lincoln. Her research interests include energy efficiency, renewable energy, numerical analysis and computer-aided design of electric machinery and power electronics devices, dynamics and control of electric machinery, permanentmagnet machines, and magnetic materials.

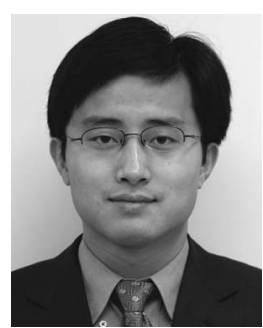

Wei Qiao (S'05-M'08) received the B.Eng. and M.Eng. degrees in electrical engineering from Zhejiang University, Hangzhou, China, in 1997 and 2002, respectively, the M.S. degree in high performance computation for engineered systems from Singapore-MIT Alliance (SMA), Singapore, in 2003, and the Ph.D. degree in electrical engineering from Georgia Institute of Technology, Atlanta, in 2008.

From 1997 to 1999, he was an Electrical Engineer with China Petroleum and Chemical Corporation (Sinopec). Since 2008, he has been an Assistant Professor of electrical engineering at the University of Nebraska-Lincoln. His research interests include renewable energy systems, smart grids, power system control and optimization, energy storage, power electronics, and condition monitoring and high-performance computation for electric power and energy systems. He is the author or coauthor of three book chapters and more than 50 papers in refereed journals and international conference proceedings.

Dr. Qiao is the Chair of the Sustainable Energy Sources Subcommittee of the IEEE Power Electronics Society and an Associate Editor of the IEEE Transactions on Industry ApPlications. He was the Technical Program Cochair of the 2009 IEEE Symposium on Power Electronics and Machines in Wind Applications. He has organized and chaired several special and regular sessions at international conferences. He was the recipient of a 2010 NSF CAREER Award and the 2010 IEEE IAS Andrew W. Smith Outstanding Young Member Award. 